\title{
Cases of thyroid cartilage metastasis as abnormal findings seen in prostate cancer patients visualized by ${ }^{68} \mathrm{Ga}-\mathrm{PSMA}-11$ $\mathrm{PET} / \mathrm{CT}$
}

\author{
Ayman M. Gaber ${ }^{*}$ (D), Rodolfo Núñez and Ebrahim Delpassand
}

\begin{abstract}
Background: ${ }^{68} \mathrm{Ga}-\mathrm{PSMA}-11 \mathrm{PET} / \mathrm{CT}$ is increasingly being used worldwide in prostate cancer patients. Accordingly, there is a pressing need for educational resources on the proper interpretation criteria that need to be used, including a deeper understanding on the pitfalls and variants that one can encounter with this new PET/CT imaging modality. ${ }^{68} \mathrm{Ga}-\mathrm{PSMA}-11 \mathrm{PET} / \mathrm{CT}$ provides very accurate staging of disease in prostate cancer, superior to what can be achieved with other standard imaging techniques. It has allowed the recognition of patterns of metastatic disease in prostate cancer that perhaps were not fully determined.

Case presentation: We present three cases of patients with advanced metastatic prostate cancer imaged with ${ }^{68} \mathrm{Ga}-\mathrm{PSMA}-11 \mathrm{PET} / \mathrm{CT}$ in which, in addition to widespread osseous metastatic disease, there is evidence of unknown and unsuspected metastatic disease in the thyroid cartilage.

Conclusion: Although rare and unusual, it is helpful to consider the possibility of prostate carcinoma metastasizing to the thyroid and cricoid cartilage, especially in prostate cancer patients with advanced widespread osseous metastatic disease.
\end{abstract}

Keywords: Prostate cancer, ${ }^{68} \mathrm{Ga}-\mathrm{PSMA}$, PET/CT, Thyroid cartilage metastasis, Case report

\section{Background}

In 2016, there were an estimated 3,110,403 men living with prostate cancer in the USA. Approximately $11.6 \%$ of men will be diagnosed with prostate cancer at some point during their lifetime. It is estimated that 191,930 new cases were diagnosed with 33,330 deaths from prostate cancer during 2020 in the USA [1]. Imaging plays an important role in many aspects in the management of this disease [2]. Since prostate-specific membrane antigen (PSMA) is known to be overexpressed in most prostate cancers, several radiolabeled ligands have been and are currently being developed to image and treat prostate cancer, using different isotopes and following

\footnotetext{
* Correspondence: ayman.maher@hotmail.com

Excel Diagnostics and Nuclear Oncology Center, 9701 Richmond Ave, Suite 122, Houston, TX 77042, USA
}

\section{Springer Open}

the theragnostic approach. By far, the most frequently used PSMA radiopharmaceutical is ${ }^{68}$ Ga-PSMA-11, which provides highly accurate $\mathrm{PET} / \mathrm{CT}$ imaging in prostate cancer [3].

The three cases that we present illustrate that due to the high sensitivity of ${ }^{68} \mathrm{Ga}$-PSMA-11 PET/CT imaging, previously unrecognized metastatic sites can be more easily detected. Cartilage metastases are rare due to the poor vasculature of this tissue. Nevertheless, metastasis to the thyroid cartilage has been previously reported in patients with different neoplastic conditions such as multiple myeloma [4], lung [5], and colon cancer [6]. Metastatic prostate cancer in the thyroid cartilage is also very rare, with-to the best of our knowledge-only five cases being described in the literature. However, at the same time, until ${ }^{68}$ Ga-PSMA PET/CT imaging has (c) The Author(s). 2021 Open Access This article is licensed under a Creative Commons Attribution 4.0 International License, which permits use, sharing, adaptation, distribution and reproduction in any medium or format, as long as you give appropriate credit to the original author(s) and the source, provide a link to the Creative Commons licence, and indicate if changes were made. The images or other third party material in this article are included in the article's Creative Commons licence, unless indicated otherwise in a credit line to the material. If material is not included in the article's Creative Commons licence and your intended use is not permitted by statutory regulation or exceeds the permitted use, you will need to obtain permission directly from the copyright holder. To view a copy of this licence, visit http://creativecommons.org/licenses/by/4.0/. 
become more routinely available, there were no wholebody imaging modalities sensitive enough to facilitate the detection of disease in the thyroid cartilage, even in present.

\section{Cases presentation}

\section{Case 1}

A 55-year-old Caucasian gentleman with castrateresistant prostate cancer was referred to our center for radioligand therapy (RLT). He had radiation therapy for prostate cancer 6 months before and started hormonal therapy 2 months before and the last chemotherapy cycle 1 month before the ${ }^{68} \mathrm{Ga}$-PSMA-11 PET/CT scan. At the time of the ${ }^{68} \mathrm{Ga}$-PSMA-11 PET/CT scan, the patient's PSA was $1000 \mathrm{ng} / \mathrm{ml}$, experiencing bone aches and dysphagia. This case shows, in addition to multiple osseous metastases, a well-defined lesion with intense radiotracer uptake in the right side of the thyroid cartilage most suspicious for a thyroid cartilage metastasis (Fig. 1).

\section{Case 2}

A 59-year-old Caucasian gentleman was diagnosed in October 2018 with metastatic castrate-resistant poorly differentiated prostate adenocarcinoma. The Gleason score was $5+4=9$. He started chemotherapy in December 2018 receiving 3 cycles, the last one in March 2019. He was also treated with hormonal therapy in November 2018. A ${ }^{68} \mathrm{Ga}$-PSMA-11 PET/CT scan was performed in March 2019 when the patient's PSA was $11.1 \mathrm{ng} / \mathrm{ml}$. This case demonstrates the presence of focal uptake of radiotracer on the right side of the thyroid cartilage and multiple osseous metastases scattered throughout the skeleton (Fig. 2). For a few months before the PET/CT scan, the patient complained of painful swallowing.

\section{Case 3}

A 66-year-old Caucasian gentleman with castrateresistant prostate cancer, Gleason score $4+4=8$, was initially treated with radical prostatectomy followed by radiation therapy a year later. Several years later, he was

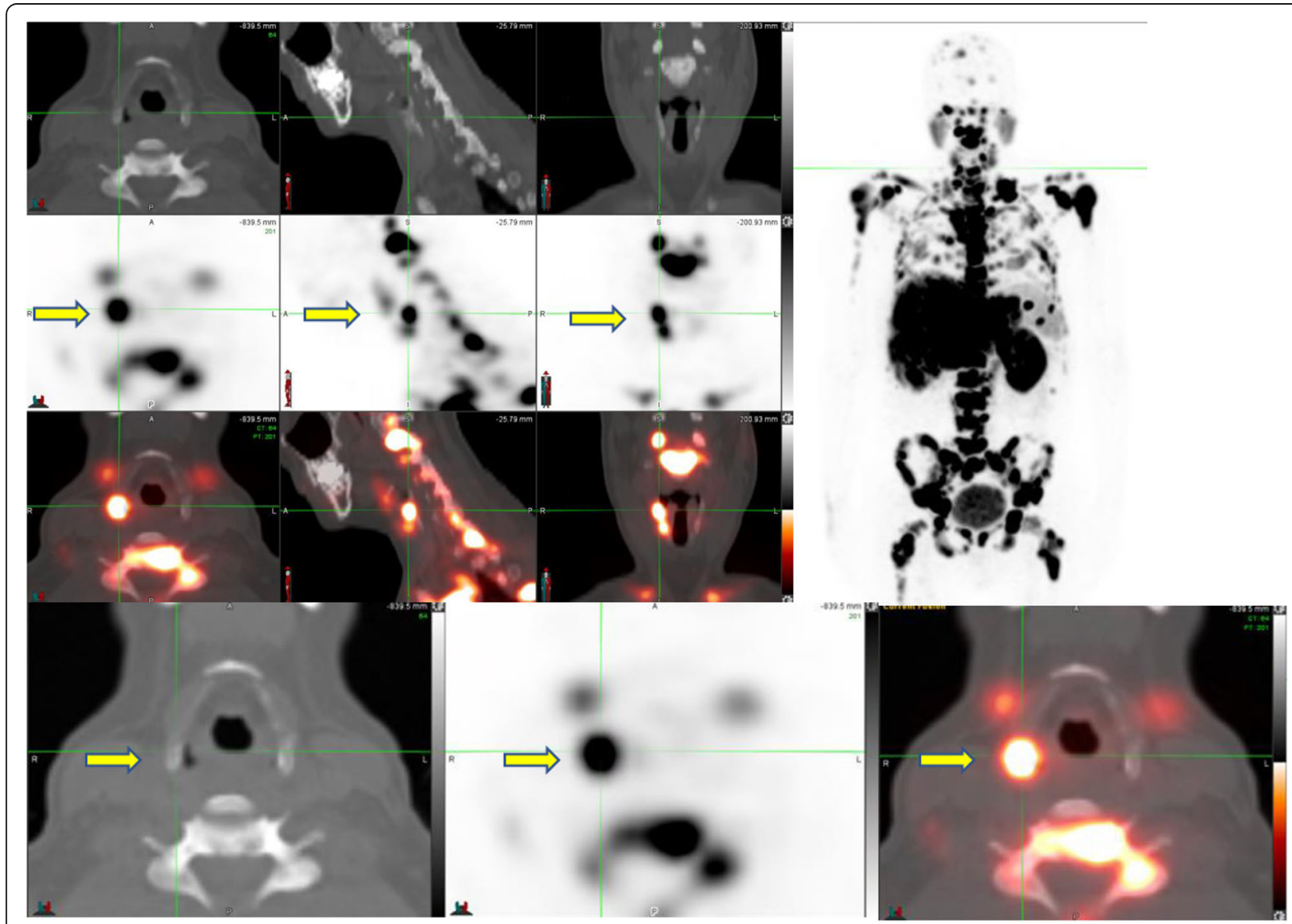

Fig. $1{ }^{68} \mathrm{Ga}$-PSMA-11 PET/CT scan images (CT image above, PET image in the middle, and fused images below) of a 55-year-old man with castrate-resistant metastatic prostate cancer. The PSA at the time of the PET/CT scan was $1000 \mathrm{ng} / \mathrm{ml}$. The axial, sagittal, and coronal images of the neck show a very avid lesion (SUV = 12) in the right side of the thyroid cartilage (arrows). The maximum intensity projection (MIP) wholebody image depicts many other osseous metastatic lesions 


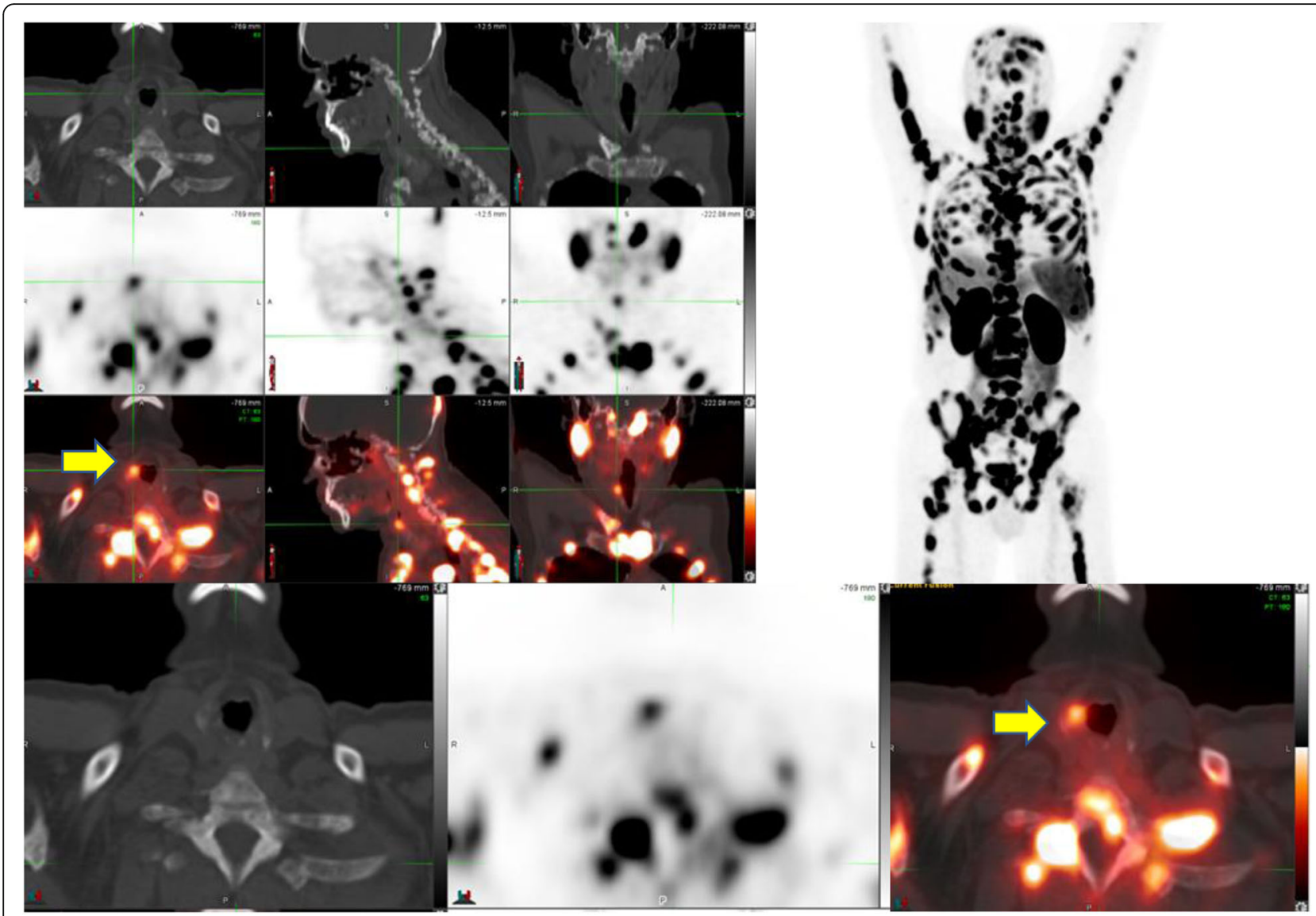

Fig. $2{ }^{68} \mathrm{Ga}$-PSMA-11 PET/CT scan images (CT image above, PET image in the middle, and fused images below) of a 59-year-old man with castrate-resistant metastatic prostate cancer. The PSA at the time of the scan was $11.1 \mathrm{ng} / \mathrm{ml}$. The axial, sagittal, and coronal images of the neck show a ${ }^{68} \mathrm{Ga}-\mathrm{PSMA}-11$ avid lesion with an SUV $=3$ (arrows) in the right side of the thyroid cartilage. The MIP whole-body image depicts other progressive metastatic lesions

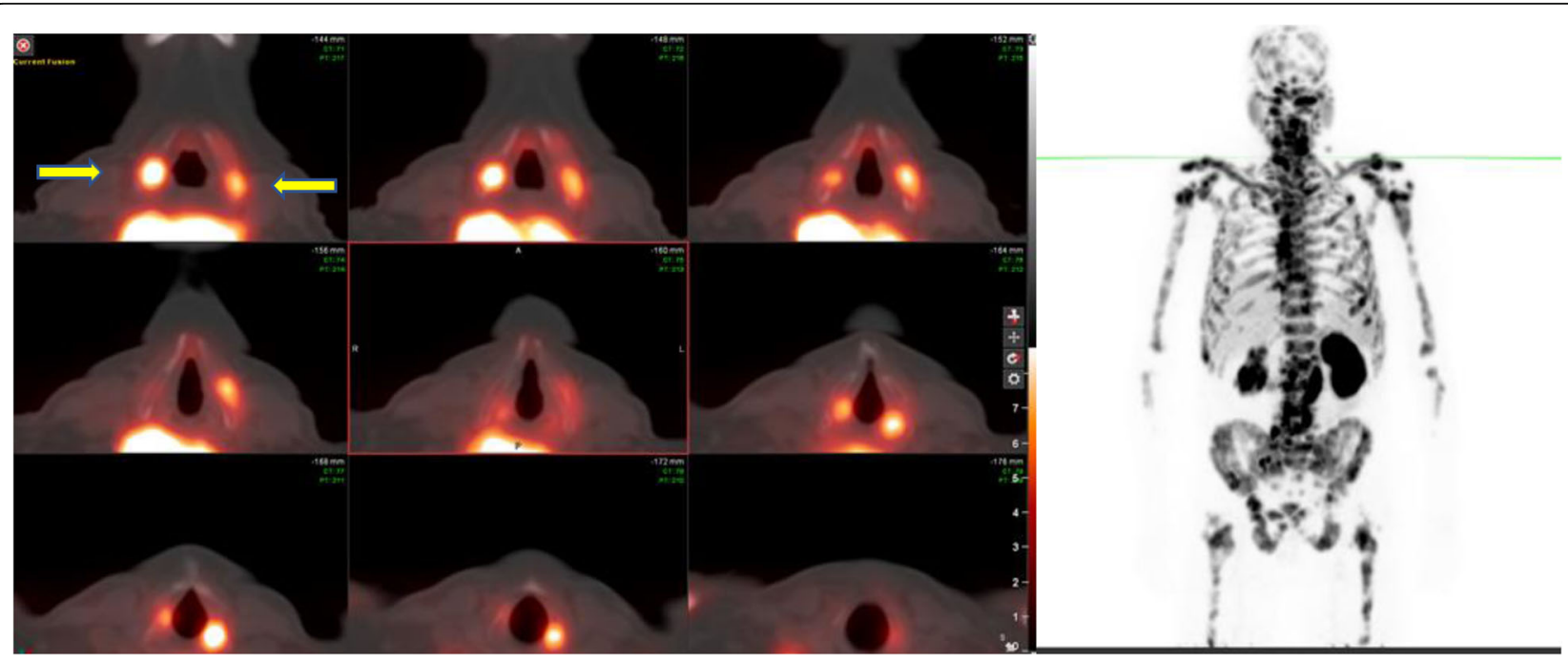

Fig. $3{ }^{68} \mathrm{Ga}$-PSMA-11 PET/CT scan images (fused PET/CT images) of a 66-year-old man with castrate-resistant metastatic prostate cancer. The PSA at the time of the scan was $973 \mathrm{ng} / \mathrm{ml}$. The fused axial images of the neck show very avid lesions at both sides of the thyroid cartilage (yellow arrows) and also on the left side of the cricoid cartilage (white arrow). MIP whole-body image shows multiple osseous metastatic lesions 
treated with chemotherapy, with the last cycle taking place 6 months before the ${ }^{68}$ Ga-PSMA-11 PET/CT scan, which was done as part of the initial work up for enrollment on a clinical trial of RLT. At the time of the PET/ CT scan, the patient's PSA was $973 \mathrm{ng} / \mathrm{ml}$. This case demonstrates the presence of two foci of intense tracer uptake on both sides of the thyroid cartilage, one single focus of disease in the left side of the cricoid cartilage and multiple osseous metastases (Fig. 3).

\section{Discussion}

Prostate cancer is considered the most common noncutaneous cancer in men in the USA. Moreover, it is among the most commonly diagnosed cancers in many developed countries and the second cause of cancer death for men in the USA. Advanced metastatic prostate cancer has a poor prognosis with survival times that ranges from 1 to 3 years. The skeleton is the most common site for prostate cancer spread. More than $80 \%$ of men who die from prostate cancer are identified with bone metastases at the time of autopsy. In contrast to many other cancers, prostate cancer predominantly forms osteoblastic metastases. The axial skeleton and proximal long bones are the most common sites of skeletal metastases. The typical routes of prostate cancer spread are hematogenous and lymphatic and by direct infiltration [7].

Thyroid cartilage malignant lesions are very rare; it accounts for 0.07 to $2 \%$ of laryngeal cancers with secondary tumors of the thyroid cartilage being extremely rare $[6,8]$. Primary lesions of the laryngeal cartilages are also rare, with the most common being chondromas and chondrosarcomas $[9,10]$.

Conventional computed tomography (CT) and magnetic resonance imaging (MRI) images demonstrate the characteristic appearance of the large primary thyroid cartilage malignant lesions; however, smaller lesions are challenging to detect. High sensitivity and accuracy of the combined PET/CT result from merging anatomic with molecular image information. The molecular information available through PET provides the functional/ metabolic characteristics of anatomic abnormalities (sometimes even on normal appearing anatomy) facilitating their characterization as malignant or benign.

Nowadays, available radioligand compounds such as ${ }^{68} \mathrm{Ga}$-PSMA-11 provide a high sensitivity and fairly specific technique for imaging with PET/CT patients with prostate cancer, with the capability-specially using the newer digital PET/CT scanners-of detecting very small lesions, often times located in anatomical structures that can appear entirely normal on the CT component of the study or even on a MRI scan. Therefore, with ${ }^{68} \mathrm{Ga}$ PSMA-11 whole-body PET/CT, it is possible to detect small volume disease in otherwise normal appearing organs. Accordingly, this new imaging technique can and does detect disease at unexpected or atypical sites for metastatic spread, further expanding our understanding on the different possible metastatic sites and different unknown pathways of tumor spread. This is the case for the metastatic disease in the thyroid cartilage.

\section{Conclusion}

As these three cases show, although rare and unusual, it is important to consider the possibility of prostate carcinoma metastasizing to the thyroid and cricoid cartilage, especially in prostate cancer patients with advanced widespread osseous metastatic disease.

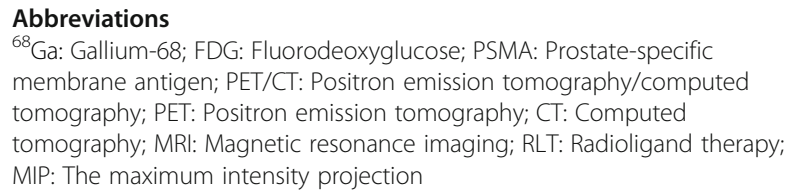

\section{Acknowledgements}

Not applicable.

\section{Authors' contributions}

Dr AG (1st author) collected the data and wrote the manuscript; Dr RN (2nd author) had provided the support in writing the paper and provided the images of the cases; and Dr ED (3rd author) helped in editing and supervising the paper. All authors have read and approved the final manuscript.

\section{Funding}

No funding sources.

\section{Availability of data and materials}

The datasets used and analyzed during the current study are available from the corresponding author on reasonable request.

\section{Declarations}

Ethics approval and consent to participate

All the studies were done as part of clinical trials, which were approved by ethical committees of BRANY IRB and the FDA with approval protocol number 124388. All patients signed the written informed consent for participation and to publish the data contained within this study form.

Consent for publication

Written consent had been obtained from the patient for the publication.

\section{Competing interests}

The authors declare that they have no competing interests.

Received: 10 March 2021 Accepted: 17 May 2021

Published online: 26 May 2021

\section{References}

1. Siegel RL, Miller KD, Jemal A (2020) Cancer statistics, 2020. CA Cancer J Clin 70(1):7-30

2. Scher HI, Morris MJ, Basch E, Heller G (2011) End points and outcomes in castration-resistant prostate cancer: from clinical trials to clinical practice. J Clin Oncol Off J Am Soc Clin Oncol 29(27):3695-3704

3. Fendler WP, Eiber M, Beheshti M, Bomanji J, Ceci F, Cho S, Giesel F, Haberkorn U, Hope TA, Kopka K, Krause BJ, Mottaghy FM, Schoder H, Sunderland J, Wan S, Wester HJ, Fanti S, Herrmann K (2017) (68)Ga-PSMA PET/CT: Joint EANM and SNMMI procedure guideline for prostate cancer imaging: version 1.0. Eur J Nucl Med Mol Imaging 44(6):1014-1024 
4. Wiesenthal AA, Nguyen BD (2007) F-18 FDG PET/CT staging of multiple myeloma with diffuse osseous and extramedullary lesions. Clin Nucl Med 32(10):797-801. https://doi.org/10.1097/RLU.0b013e318148afdc

5. Ozcan Kara P, Kara Gedik G, Sari O, Ozbek O (2011) Rare thyroid cartilage and diaphragm metastases from lung cancer visualized on F-18 FDG-PET/CT imaging. Mol Imaging Radionucl Ther 20(2):70-72. https://doi.org/10.4274/ MIRT.019882

6. Bracanovic D, Vukovic V, Janovic A, Radosavljevic D, Rakocevic Z (2017) Hyoid bone and thyroid cartilage metastases from sigmoid colon adenocarcinoma: a case report. Balkan Med J 34(3):278-280. https://doi. org/10.4274/balkanmedj.2015.1817

7. Bubendorf L, Schopfer A, Wagner U, Sauter G, Moch H, Willi N, Gasser TC, Mihatsch MJ (2000) Metastatic patterns of prostate cancer: an autopsy study of 1,589 patients. Hum Pathol 31(5):578-583. https://doi.org/10.1053/hp.2 000.6698

8. Escudero RM, Amo FH, Martinez MC, Jimenez JT, Alonso AH, Pinies GO, Fernandez CH (2011) Metastatic prostate cancer on the thyroid cartilage: unusual symptoms of prostatic adenocarcinoma. Case report, Arch Esp Urol 64(2):132-135

9. Moerman M, Kreps B, Forsyth R (2009) Laryngeal chondrosarcoma: an exceptional localisation of a not unfrequent bone tumor. Sarcoma 2009: 394908

10. Oliveira JF, Branquinho FA, Monteiro AR, Portugal ME, Guimaraes AM (2014) Laryngeal chondrosarcoma--ten years of experience. Braz J Otorhinolaryngol 80(4):354-358. https://doi.org/10.1016/j.bjorl.2014.05.004

\section{Publisher's Note}

Springer Nature remains neutral with regard to jurisdictional claims in published maps and institutional affiliations.

\section{Submit your manuscript to a SpringerOpen ${ }^{\circ}$ journal and benefit from:}

- Convenient online submission

- Rigorous peer review

- Open access: articles freely available online

High visibility within the field

- Retaining the copyright to your article

Submit your next manuscript at $\boldsymbol{\nabla}$ springeropen.com 